\title{
Estimating the Level of Some Inflammatory Cytokines in the Serum of Women Exposed to Abortion and the Relationship with Toxoplasmosis
}

\author{
Raqaa Abd-Almuhsin Mohammed ${ }^{1 *}$, Salih Ismaiel Al-Ubaidi², Adeba Younis Shareef ${ }^{3}$, \\ Hammo Al-Noaman ${ }^{4}$ \\ ${ }^{1 * 2}$ Nineveh Health Directorate, Ministry of Health, Mosul, Iraq \\ ${ }^{3,4}$ Department of Biology, College of Science, University of Mosul, Mosul, Iraq \\ E-mail: ${ }^{1 *}$ raqaamuhsin82@gmail.com, ${ }^{3}$ shareefadeeba@yahoo.com
}

(Received September 20, 2020; Accepted November 15, 2020; Available online June 01, 2021)

DOI: 10.33899/edusj.2020.128415.1113, ( ) 2021, College of Education for Pure Science, University of Mosul.

This is an open access article under the CC BY 4.0 license (http://creativecommons.org/licenses/by/4.0/).

\begin{abstract}
This study includes the collection of (90) blood samples, eighty samples belongs to patients experienced to spontaneous or recurrent abortions, and the ten samples from women with normal pregnancy. The results showed a significant increase in the levels of cytokines in patients serum as their concentrations were $(218.15 \pm 105.1 \mathrm{pg} / \mathrm{L}$ for $\mathrm{IL}-1 \beta, 63.10 \pm 35.17 \mathrm{ng} / \mathrm{L}$ for TNF- $\alpha$ and $31.77 \pm 25.3 \mathrm{ng} / \mathrm{ml}$ for IFN- $\gamma)$ compared to the control as it $(151.0 \pm 0.76 \mathrm{pg} / \mathrm{L}, 34.96 \pm 0.42 \mathrm{ng} / \mathrm{L}$ and $11.15 \pm 3.49 \mathrm{ng} / \mathrm{ml})$ for the cytokines respectively. The level of cytokines reached $(352.18 \mathrm{pg} / \mathrm{L}, 117.8$ $\mathrm{ng} / \mathrm{L}$ and $63.8 \mathrm{ng} / \mathrm{ml}$ ) for $\mathrm{IL}-1 \beta, \mathrm{TNF}-\alpha$ and $\mathrm{IFN}-\gamma$ respectively in women infected with Toxoplasmosis compared to non-infected women $(337.1 \mathrm{pg} / \mathrm{L}, 101.3 \mathrm{ng} / \mathrm{L}$ and $54.06 \mathrm{ng} / \mathrm{ml})$. This indicate that toxoplasmosis has a role in the induction of immune system.
\end{abstract}

Keyword: Cytokine, Toxoplasmosis, Woman abortion

تقدير مستوى بعض السايتوكينات الالتهابية في أمصال النساء المجهضات وعلاقته بداء المقوسات

رقاء عبد الححسن محمد صالح اسماعيل العبيدي1"، أديبة يونس شريف حمو النعمان2

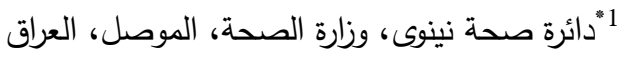

2قسم علوم الحياة، كلية العلوم، جامعة الموصل، الموصل، العراق، العراق

الخلاصة

اشتملت الدراسـة على جمـع (90) عينـة دم، (80 ) منهـا مـن نسـاء عـانين من الاجهاض التلقائي او الإجهاض المتكرر

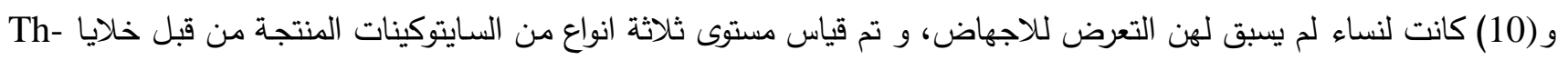

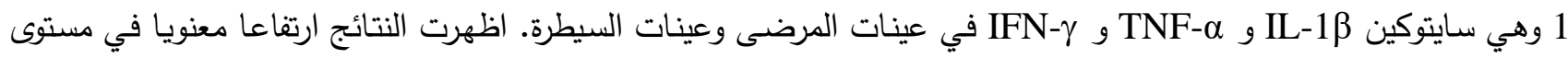

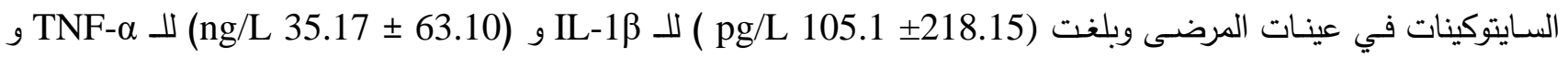
(ng/ml 25.3 ـ 21.77$)$ 
و للسايتوكينات الثلاثتة على التوالي. وبينت النتائج حدوث ارتفاع في مستوى السايتوكينات 3.49 (ng/ml 3.11 .15$)$

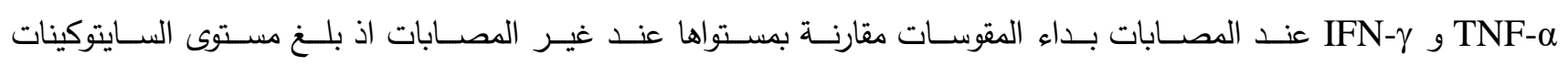

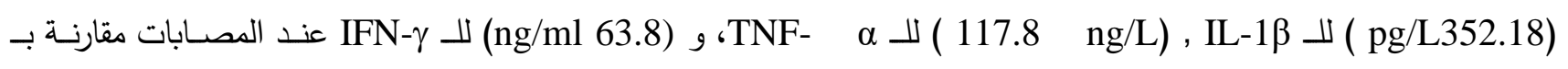
(ng/L337.1) و (ng/L 101.3) و (nt.06) للسايتوكينات الثلاثة على التوالي عند غير المصابات مما يثير إلى أن الإصابة بداء المقوسات لها دور في حث الاستجابات المناعية.

الكلمات المفتاحية: المقوسات، اجهاض النساء

\section{المقدمة}

تمثل منطقة التداخل بين الام والجنين ظاهرة لتعايش كائنين يحملان خلفيات وراثية مختلفة إذ يبدأ جسم المرأة بعد ساعات

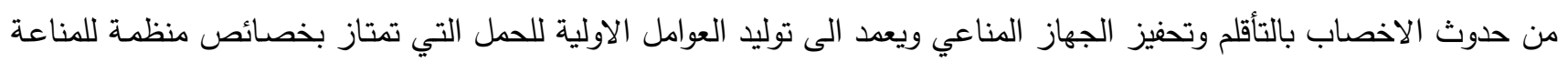

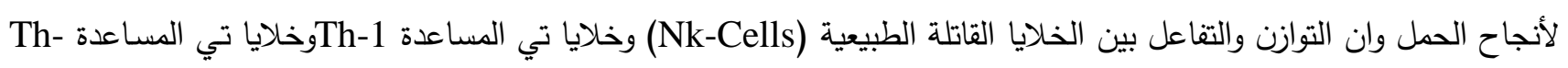

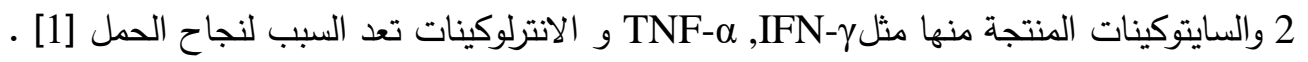

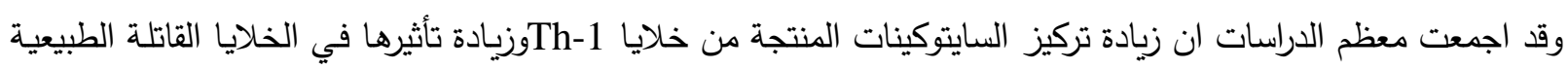

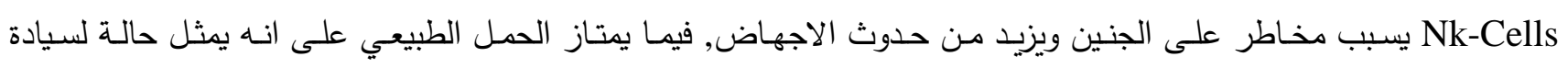

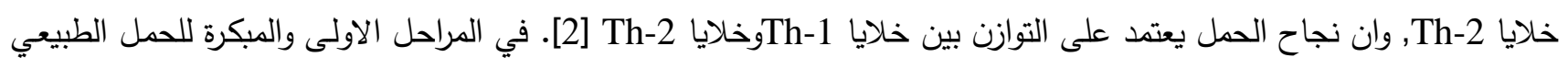
تكون سايتوكينات خلايا Th-1ضرورية من اجل تحوير الاوعية الدموية وتكوينها Vasculo genesis، وهذه العملية مهمة لإنجاح

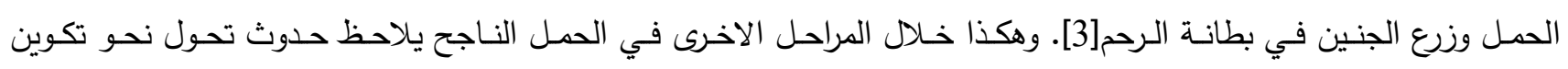

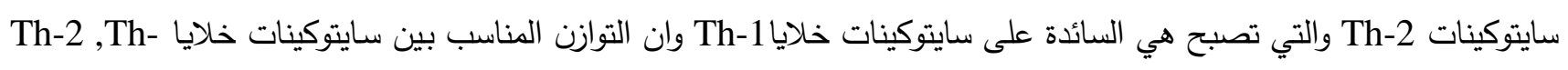

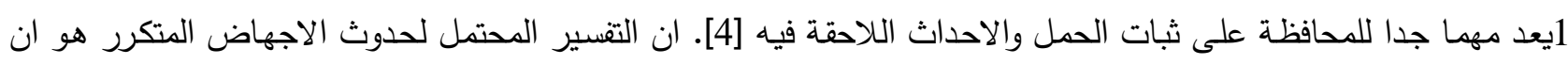
السايتوكينات مـا قبل الالتهابية (y cytokinesProinflammator) قد تعمل على تحويل الخلايا القاتلة الطبيعية (Nk-Cells)

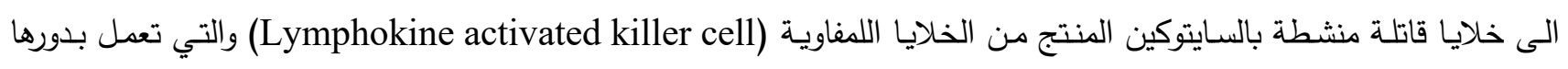

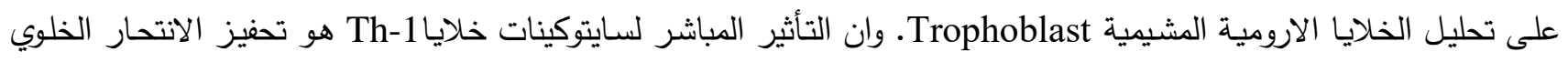

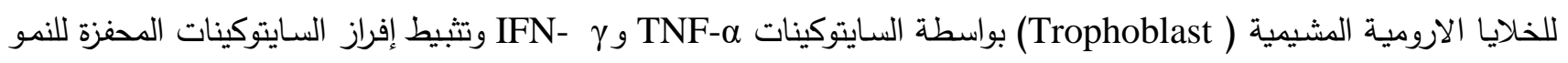
من الخلايا الطلائية الرحمية وكذللك تعمل سايتوكينات خلايا Th-1 على تحفيز تتشيط اليات التجلط والتي قد تؤدي لاحقا الى ولى

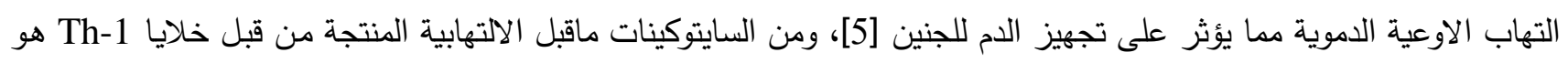

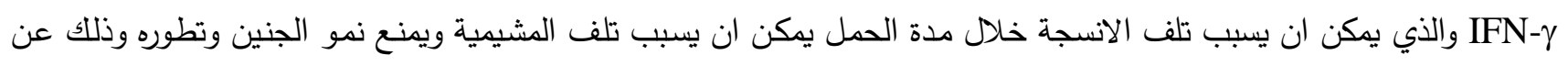

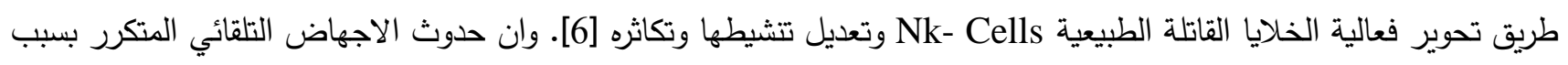

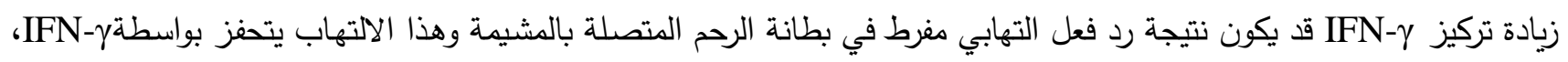

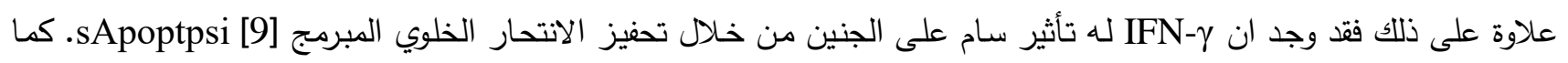
يعد عامل النخر الخلوي Tumor Necrosis Factor-

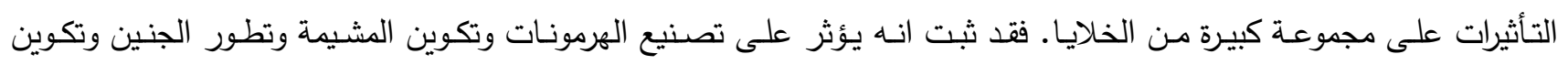

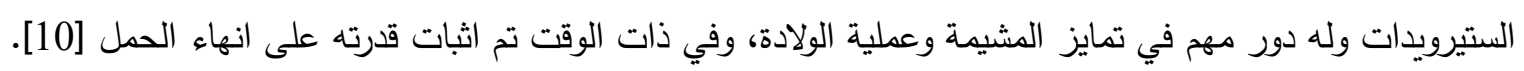




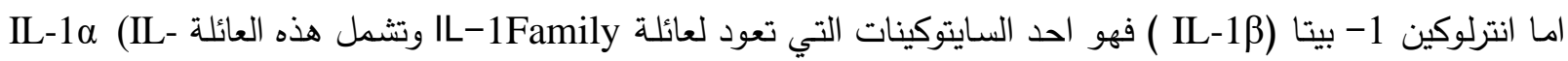

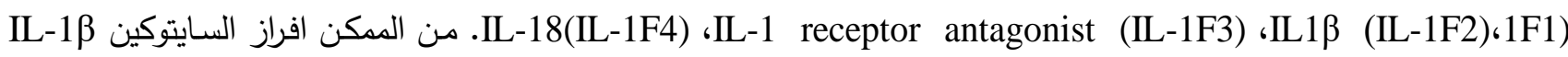
خارج الخلايا ولهذا فهو عادة ما يوجد في المصل وفي الافرازات، وهو يلعب دورا مهما في تتظيم الاستجابة الالتهابية [11] ، فهو يحفز افراز العديد من الوسائط الالتهابية مثل -TNF-A gIL-8 IL6 من خلادل تأثيره على العديد من الخلايا مثل الخلايا

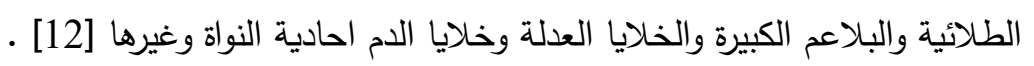

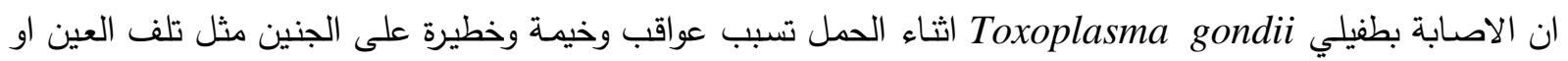

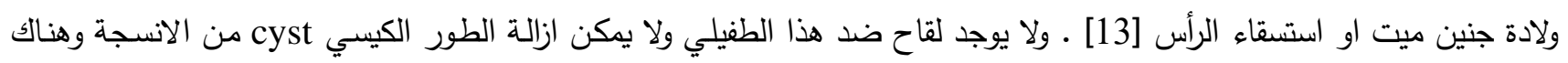

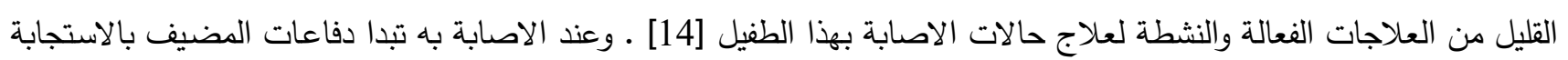

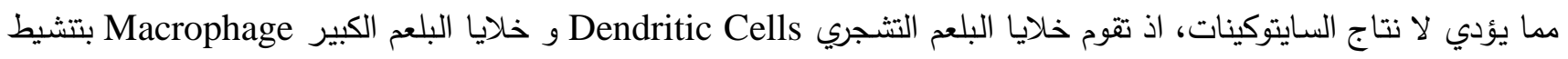

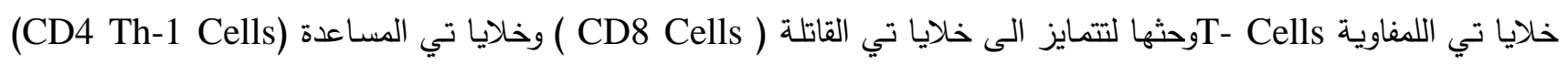

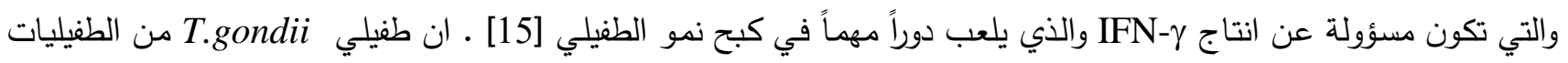
داخل خلوية وله تخصصية واطئة للمضيف ويملك تخصصية واطئة اذ يصيب الثديات وكذلك الطيور ، يتوطن هذا الطفيلي في جميع انحاء العالم مع ذلك فان نسبة (15-85\%) من الاشخاص يكونون مصابين مع عدم وجود اعراض [16] ـ ـ يعد طفيلي داء المقوسات من الطفيليات المهمة والتي تسبب اصابات مشتركة بين الحيوان والانسان وهو من اكثر العوامل المعدية انتشارا في العراق

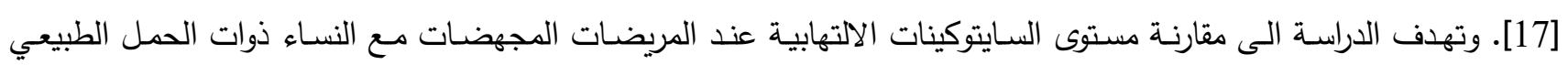

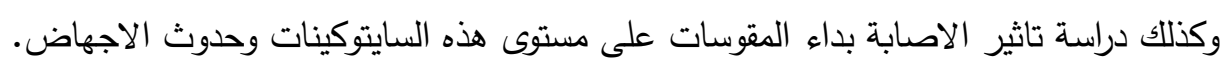

\section{المواد وطرائق العمل}

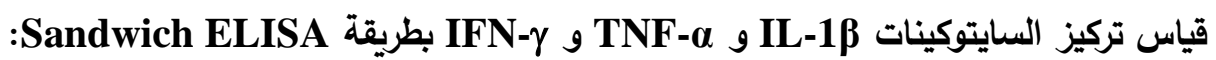
مبدأ القياس:

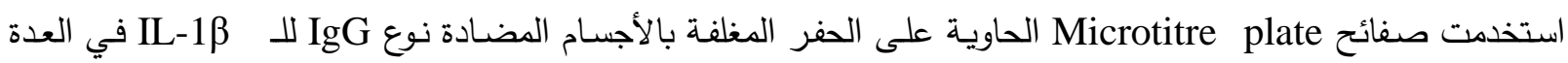

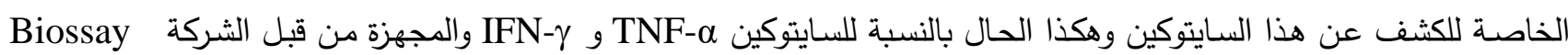
Technology Laboratory

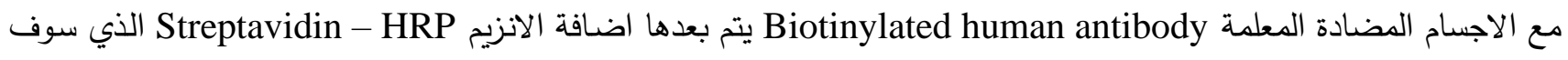
يرتبط مع الاجسام المضادة المعلمة اما الانزيم غير المرتبط فيتم ازالته بعملية الغسل بعد التحضين لفترة زمنية. بعدها يتم اضافة المادة الاساس للانزيم والذي يؤدي لحدوث تفاعل لوني , تتتاسب شدته مع تركيز السايتوكين في العينة. ثم يتم انهاء التفاعل باضافة محلول الايقاف Acidic Stop Solution وتقاس الامتصاصية عند طول موجي nm (450). 
Journal of Education and Science (ISSN 1812-125X), Vol: 30, No: 2, $2021(33-41)$

جدول(1) مكونات عدة فحص السايتوكينات

\begin{tabular}{|c|c|}
\hline الكمية ml والحجم & 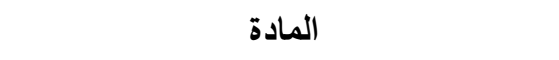 \\
\hline $0.5 \mathrm{ml}$ & محلول قياسي \\
\hline $3 \mathrm{ml}$ & محلول لتخفيف الـحلول القياسي \\
\hline $6 \mathrm{ml}$ & Streptavidin - HRP \\
\hline $6 \mathrm{ml}$ & محلول ايقاف التفاعل \\
\hline $6 \mathrm{ml}$ & A محلول المادة الاساس A \\
\hline $6 \mathrm{ml}$ & B محلول المادة الاساس B \\
\hline $20 \mathrm{ml}$ & المحلول الدارئ المركز للغسل \\
\hline $1 \mathrm{ml}$ & Biotinylated human antibody \\
\hline شرائط x8 حفرة 12 & صفيحة ايلايزا مغلفة مسبقا بالاجسام المضادة \\
\hline عدد 1 كتيب & 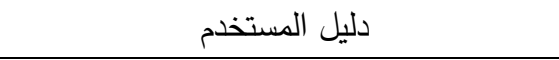 \\
\hline عدد 2 غطاء & غطاء الصفيحة \\
\hline عدد 1 كيس & كيس حافظ للصفيحة \\
\hline
\end{tabular}

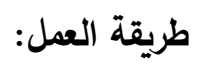

تحضير المحاليل وتخفيفها:

أ-تخفيف المحلول القياسي:

1- تركت العينات في المختبر لتصل درجة حرارة الغرفة.

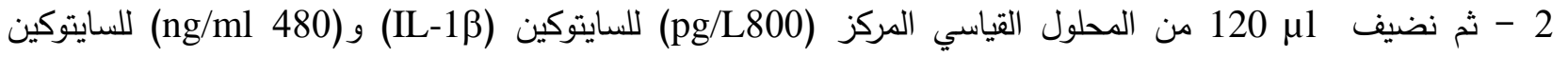

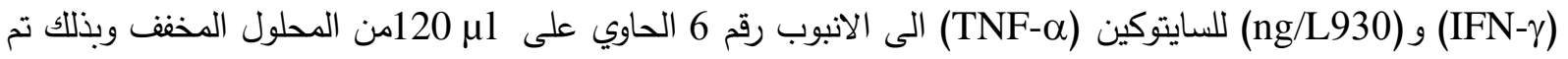

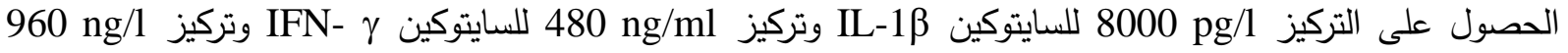
للسايتوكين $\alpha$ TNF- ترك المزيج لمدة 15 دقيقة ثم حضرت تخافيف مضاعفة من المحلول القياسي وذلك بنقل بر 120 من الانبوب رقم 6 الى الانبوب رقم 5 الحاوي على 1201 من المحلول المخفف وهكذا نستمر للحصول على التخافيف

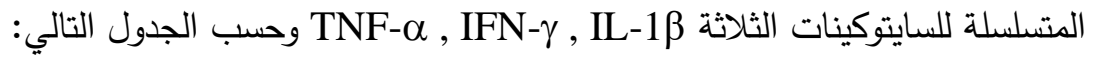

الجدول (2) تحضير تخافيف السايتوكينات

\begin{tabular}{|c|c|c|c|c|c|}
\hline الانبوب رقم 5 & الانبوب رقم 4 & الانبوب رقم 3 & الانبوب رقم 2 & الانبوب رقم 1 & السايتوكينات \\
\hline $4000 \mathrm{pg} / \mathrm{L}$ & $2000 \mathrm{pg} / \mathrm{L}$ & $1000 \mathrm{pg} / \mathrm{L}$ & $500 \mathrm{pg} / \mathrm{L}$ & $250 \mathrm{pg} / \mathrm{L}$ & IL-1 $\beta$ \\
\hline $240 \mathrm{ng} / \mathrm{ml}$ & $120 \mathrm{ng} / \mathrm{ml}$ & $60 \mathrm{ng} / \mathrm{ml}$ & $30 \mathrm{ng} / \mathrm{ml}$ & $15 \mathrm{ng} / \mathrm{ml}$ & IFN- $\gamma$ \\
\hline $480 \mathrm{ng} / \mathrm{L}$ & $240 \mathrm{ng} / \mathrm{L}$ & $120 \mathrm{ng} / \mathrm{L}$ & $60 \mathrm{ng} / \mathrm{L}$ & $30 \mathrm{ng} / \mathrm{L}$ & TNF- $\alpha$ \\
\hline
\end{tabular}

ب- تحضير المحلول الداريء للغسل ( Wash Buffer ): تم تخفيف ml 20 من داريء الغسل المركز 25 مرة بماء مقطر حجمه ml.

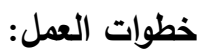

1 -تم تحضير كل المحاليل , المحلول القياسي والعينات ثم تركت بدرجة حرارة الغرفة. 2- تم تحضير الشرائط اللازمة لعدد العينات اما الثرائط التي لم تستخدم تم خزنها بدرجة حرارة (2-8) مْ 
3 - تم اضافة 30 1 50 من المحلول القياسي الى الحفر الستة الاولى. 4 - واضيف بر 40 من المصل الى الحفر الباقية وتم اضافة بl 10 من Biotinylated Antibody للحفر الخاصـة بالعينات

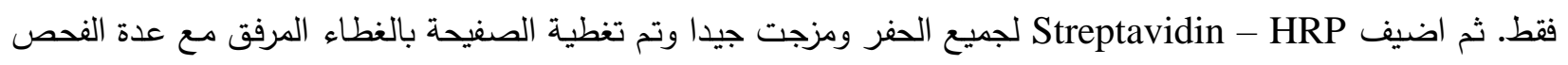
وحضنت لمدة ساعة بدرجة حرارة (37) مْ

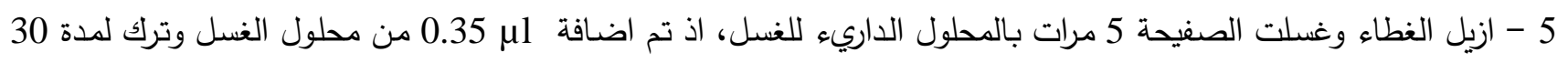
ثانية لكل غسلة، ثم قلبت الصفيحة على ورقة للتتشيف وامتصاص محلول الغسل الزائد من الصفيحة.

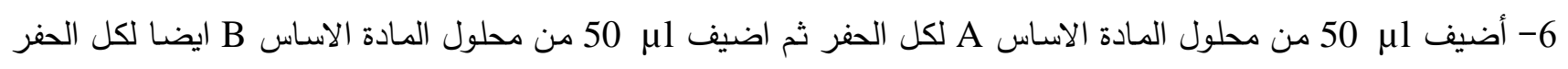
وحضنت الصفيحة بعد تغطيتها لمدة (10) دقائق بدرجة حرارة (37) م في الظلام.

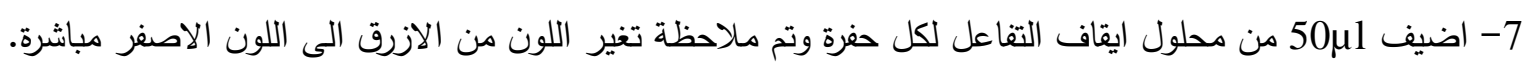
8 - تم قياس الكثافة الضوئية لكل حفرة باستخدام Microplate reader عند طول موجي 450nm تمت قراءة النتائج خلال 10دقائق من اضافة محلول ايقاف التفاعل Stop Solution. وتم حساب التركيز من خلال استخدام المنحني القياسي الذي فئي يوضح العلاقة بين تركيز السايتوكينات والكثافة الضوئية للعينات القياسية. فحص الكشف عن الاصابة بداء المقوسات باستخدام طريقة التلازن المناعي تركيز مبدأ الفحص: ان محلول مستضدات طفيلي داء المقوسات هو عبارة عن معلق يتكون من جزيئات بوليستيرين المغلف سطحها بمستضدات

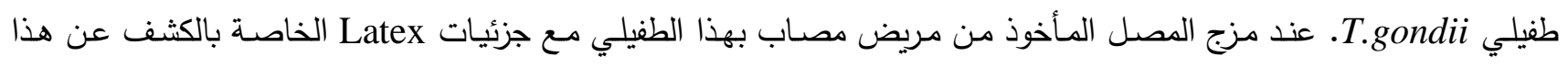

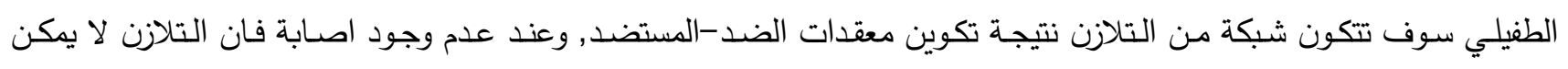

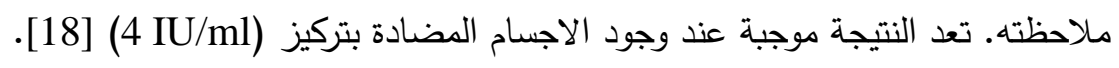

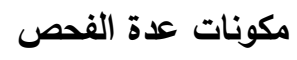
1- محلول جزيئات Latex , يتم مزج المحلول جيدا قبل الاستخدام للتأكد من تجانسه.

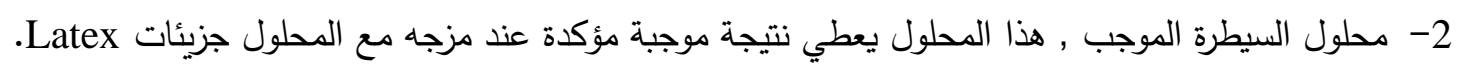

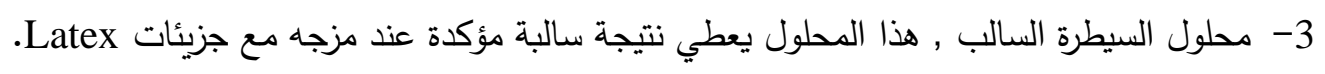
4- شريحة يتم اجراء التفاعل عليها و انبوبة وماصة للمزج.

طريقة العمل: - م

1- وضعت وحضرت جميع المحاليل وكذلك المصل عند درجة حرارة الغرفة.

2- خففت العينة اي المصل (1/2-1/8) باستخدام المحلول الملحي الفسلجي (NaCl 0.9\%) 3- تم وضع قطرة واحدة (5011) من المصل المخفف على الثريحة الخاصة للفحص باستخدام الماصة المجزة مع عدة الفحص. 4- تم اضافة (251 25) من محلول Latex الى الثريجة باستخدام الماصة الخاصة المجهزة. 5- تم مزج القطرتين جيدا و وذلك بتدوير الشريحة. 6- تم ملاحظة ومراقبة تكون التلازن من عدمه خلال مدة لم تتجاوز (4) دقائق.

\section{النتائج والمناقشة}

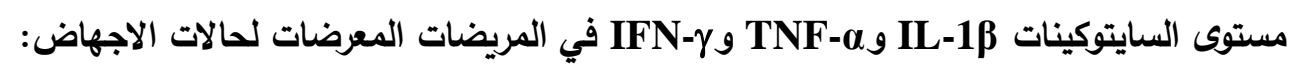




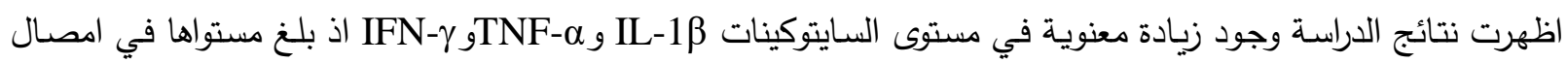

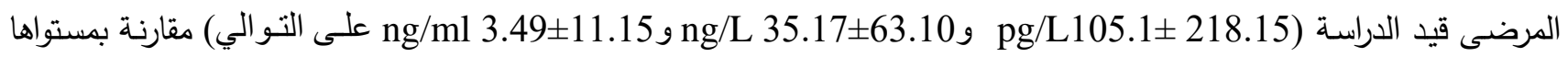

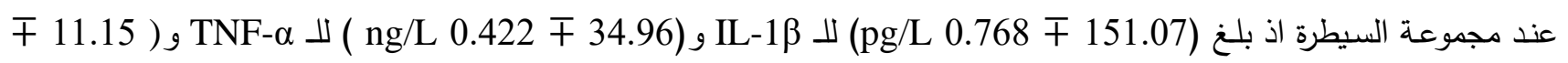

IFN- $\gamma$ ل $(\mathrm{ng} / \mathrm{ml} 3.49$

وكان الفرق معنوياً عند مستوى P P Pما موضح في الشكل (1).

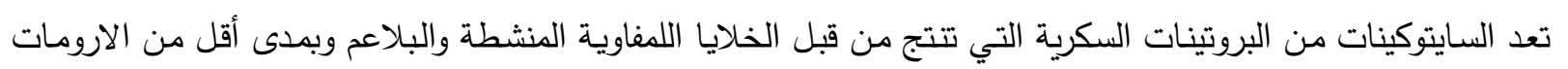

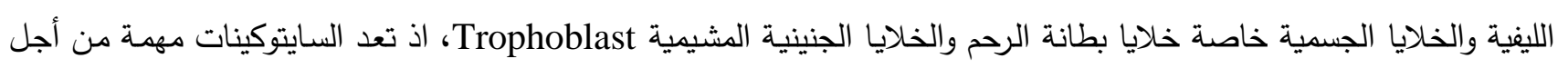

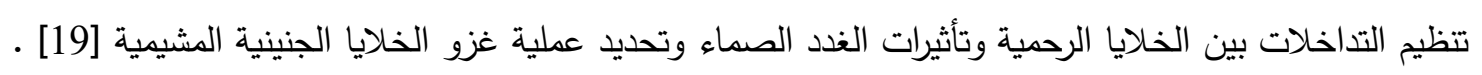

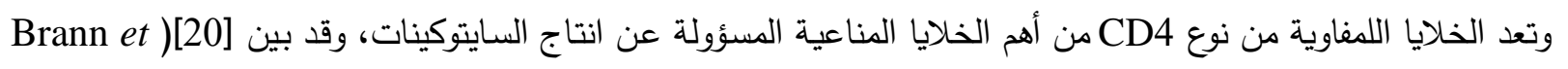

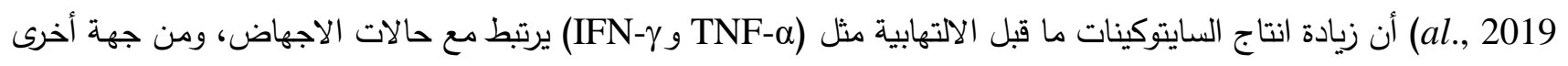

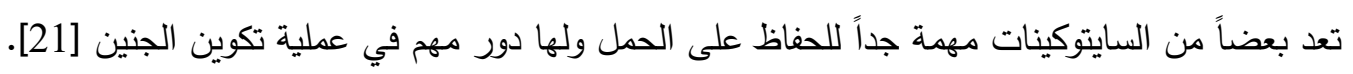

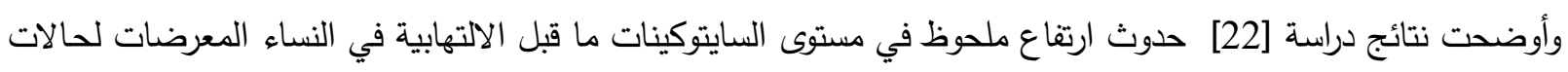
الاجهاض المتكرر بعينات السيطرة.

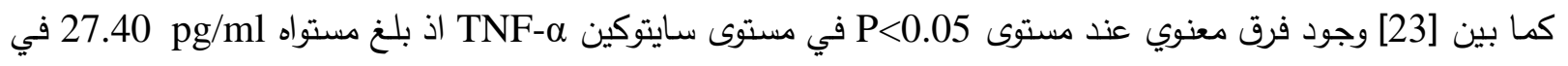
عينات المريضات المجهضات فيما كان 8.94 pg/ml عند مجموعة السيطرة وتوصل من خلال هذه النتيجة الى العلاقة الوثيقة بين

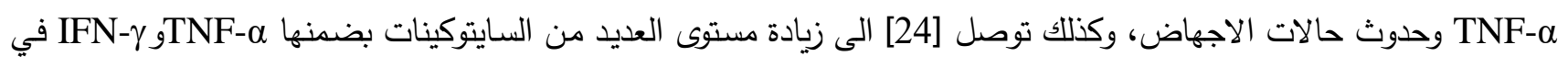
النساء اللواتي يعانين من الاجهاض المتكرر مقارنـة بالنساء ذوات الحمل الناجح. وتم التحري في دراسـة [25] عن السايتوكينات

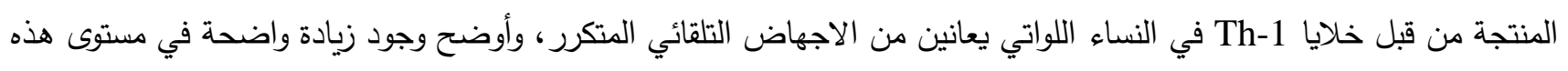
السايتوكينات في مجموعة المريضات مقارنة مع مجموعة السيطرة. كما تم توضيح دور سايتوكين IFN- وعلاقته بحالة الاجهاض من قبل [26] ، اذ لاحظوا الزيادة المعنوية في مستواه للى النساء اللواتي يعانين من مضاعفات الحمل والاجهاض والذي بلغ مستواه لديهن 31.88 pg/ml مقارنة بمستواه عند عينات السيطرة اذ كان 13.8 pg/ml

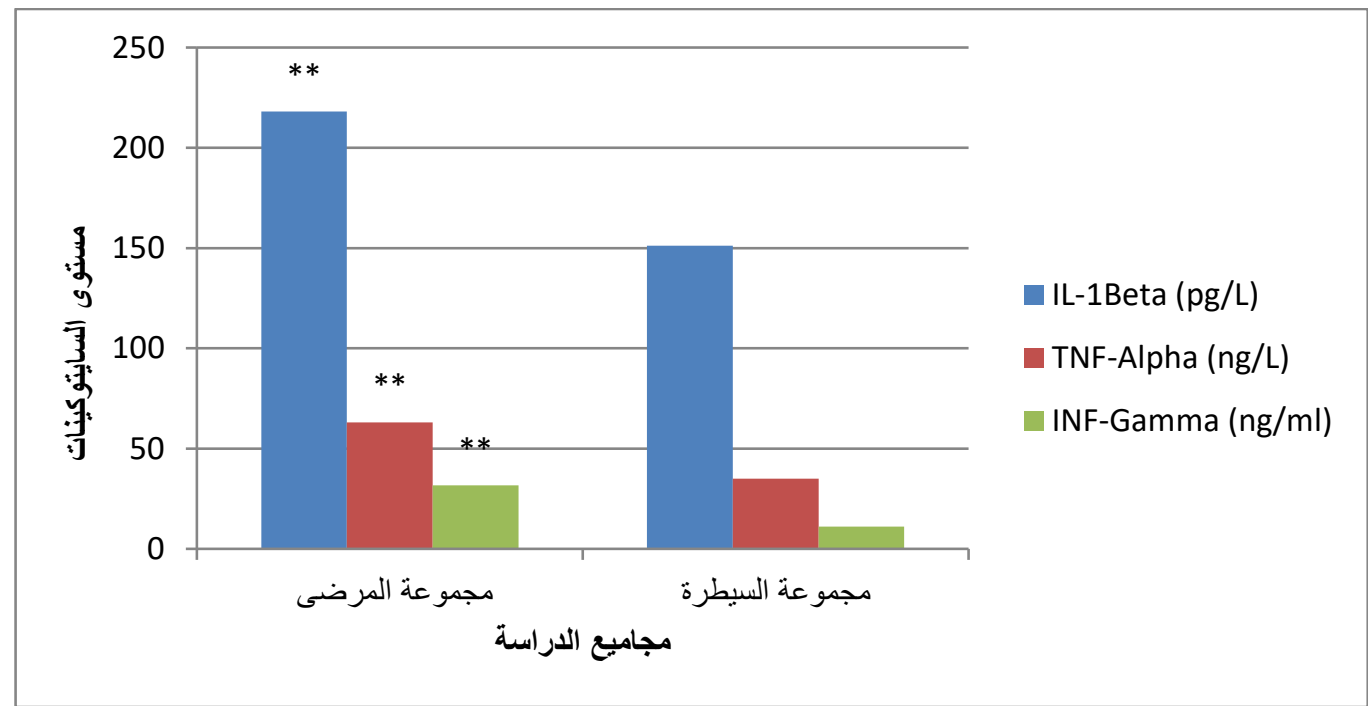

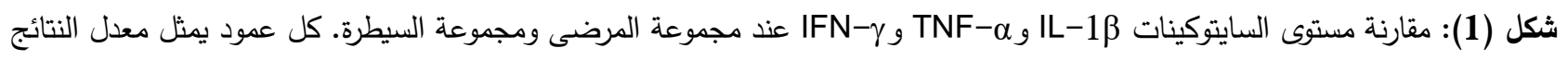

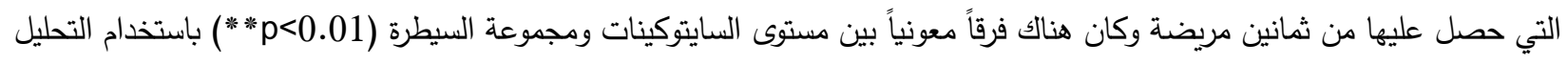
T-test الاحصائي 
التحري عن الاصابة بداء المقوسات Toxoplasmosis: تم التحري عن وجود الأجسام المضادة لطفيلي T.gondii في (22) عينة مصل لمريضات الظهرن بات بنائج موجبة للاصابة بمتلازمـة الدهون الفوسفاتية وتم اجراء الفحص باستخدام طريقـة تلازن اللاتكس المعتمد على استخدام جزيئات Latex المغلفـة

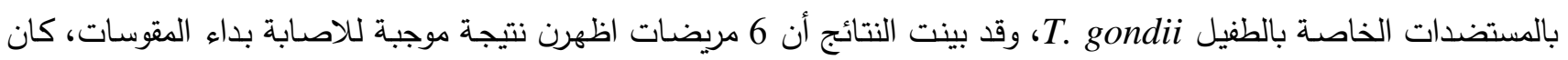
(5) منهن ضمن المجموعة المعرضة لثلاث اجهاضات أو أكثر ومريضة واحدة كانت قد تعرضت لحالتي اجهاض.

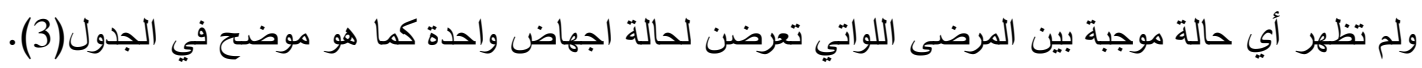

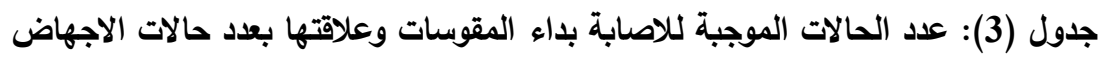

\begin{tabular}{|c|c|c|c|c|c|}
\hline $\begin{array}{c}\text { نسبتها المئوية } \\
\text { \% }\end{array}$ & عدد العينات السالبة & نسبتها المئوية & عدد العينات الموجبة & عدد العينات & / المحامع المدابة بداء \\
\hline$\% 100$ & 1 & 0 & 0 & 1 & مجموعة 1 \\
\hline$\% 75$ & 3 & $\% 25$ & 1 & 4 & مجموعة 2 \\
\hline$\% 70$ & 12 & $\% 29.4$ & 5 & 17 & مجموعة 3 \\
\hline$\% 72.7$ & 16 & $\% 27.2$ & 6 & 22 & المجموع \\
\hline
\end{tabular}

* المجموعة 1 (مريضات ذوات اجهاض واحد)، المجموعة 2 (مريضات تعرضن لاجهاضين)، الهجموعة 3 (مريضات تعرض لثلاث اجهاضات او اكثر)

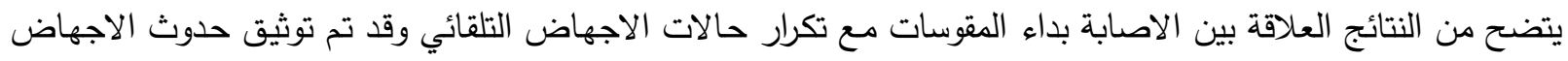

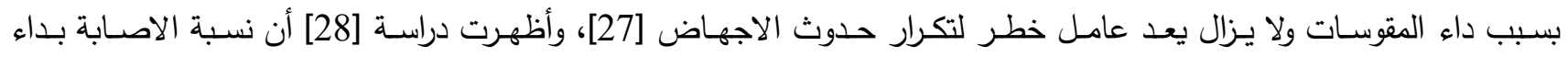
المقوسات بلغت 49.7\% في النساء المعرضات للاجهاض، فيما سجل [29] نسبة 42.6\% للاصـابة بداء المقوسات وبينت نتائج

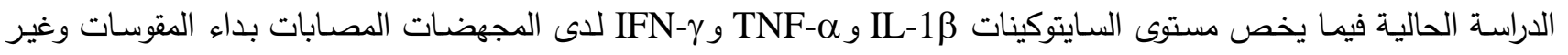

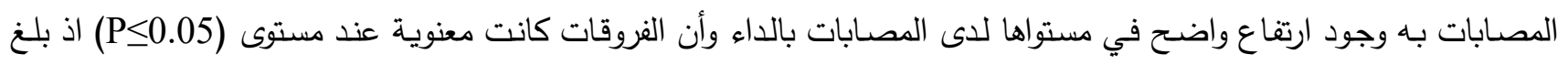

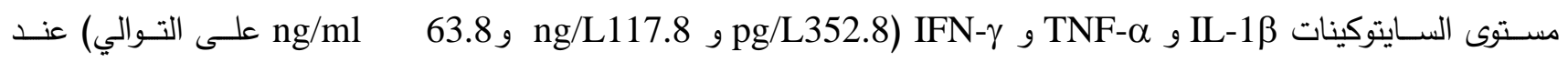

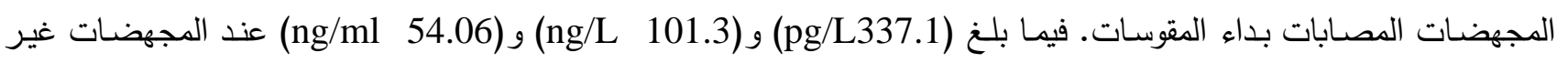

المصابات بداء المقوسات وكما موضح في الجدول (4).

جدول (4): مستوى السايتوكينات لمجموعة المجهضات المصابات بداء المقوسات ومقارنتها مع مجموعة المجهضات غير المصابات

\begin{tabular}{|c|c|c|c|c|}
\hline $\begin{array}{c}\text { IFN- } \gamma \text { مستوى } \\
\text { ng/ml }\end{array}$ & $\begin{array}{c}\text { TNF- } \alpha \text { مستوى } \\
\text { ng/L }\end{array}$ & $\begin{array}{c}\text { IL-1 مستوى } 1 \text { Pg/L } \\
\text { Pg/L }\end{array}$ & 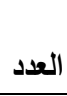 & مجاميع المرضى \\
\hline 63.8 & 117.8 & 352.8 & 6 & المجهضات المصابات بداء المقوسات \\
\hline 54.06 & 101.3 & 337.1 & 16 & المجهضات غيرالمصابات بداءالمقوسات \\
\hline 0.05 & 0.01 & 0.001 & 22 & P-value \\
\hline
\end{tabular}

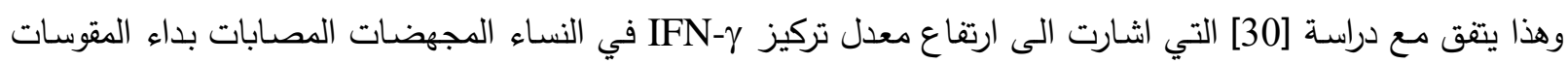

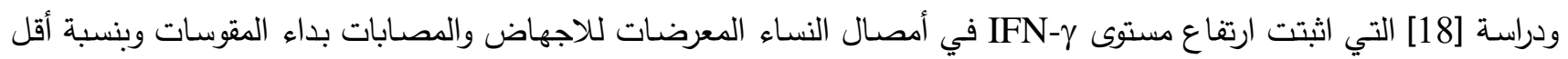

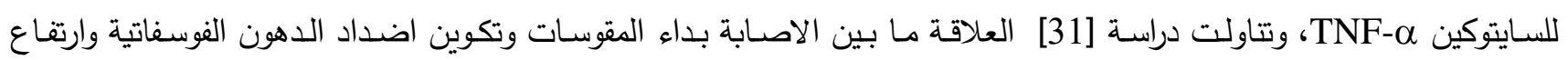
مستوى السايتوكينات ما قبل الالتهابية في النساء المجهضات، حيث بينت دراستهم ارتفاعاً في مستوى الأجسام المضادة للدهون

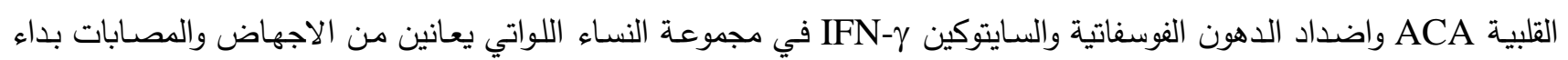




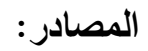

[1] Kaislasuo, J.; Simpson, S.; Petersen, J. F.; Peng, G.; Aldo, P.; Lokkegaard, E. and Mor, G. (2020). American J. Rep. Immun., 83(1), e13195.

[2] Ghasemnejad-Berenji, H.; Novin, M. G.; Hajshafiha, M.; Nazarian, H.; Hashemi, S. M.; Ilkhanizadeh, B.,; Ghasemnejad-Berenji, M. (2018). Biomed. Pharmac., 107:1277-1285.

[3] Demir, R.; Yaba, A.; Huppertz, B. (2010). Acta Histochemica, 112(3): 203-214.

[4] Dekel, N., Gnainsky, Y., Granot, I., Racicot, K., and Mor, G. (2014). American J. Reproduc. Immun. 72(2):141-147.

[5] Raghupathy, R.; Kalinka, J. (2008). Front Biosci., 13(1): 985-94.

[6] Li, Y., Wang, Y., Ding, X., Duan, B., Li, L., \& Wang, X. (2016). Repr. Scien., 23(10):14021408.

[7] Robertson, S. A. ; Moldenhauer, L. M. (2014). Int. J. Dev. Biol., 58(2-3-4): 205-217.

[10] Giannubilo, S. R.; Landi, B.; Pozzi, V.; Sartini, D.; Cecati, M.; Stortoni, P.; Emanuelli, M. (2012). Cytokine, 58(1):50-56.

[11] Dinarello, C. A. (2010). Europ. J. Immun. 40(3):599-606.

[12] Linjawi, S.; Li, T. C.; Laird, S. ; Blakemore, A. (2005). Fertility and Sterility, 83(5): 1549-1552.

[13] Wallon, M. ; Peyron, F. (2018). Pathogens, 7(1): 25.

[14] Montazeri, M.; Sharif, M.; Sarvi, S.; Mehrzadi, S.; Ahmadpour, E. ; Daryani, A. (2017). Frontiers in Microbiology, 8: 25.

[15] Sasai, M.; Pradipta, A. ; Yamamoto, M. (2018). Int. Immun., 30(3): 113-119.

[16] El-Sherbini, M. S.; Abd El-Aal, A. A.; El-Sherbiny, W. S.; Attia, S. S.; Aziz, I. Z. A.; Nasr, G. M.,. ; Badr, M. S. (2019). Egyptian J. Med. Hum. Gen., 20(1): 3.

[17] AL-Mossawei, M. T.; AL-Mossawei, H. M.; AL-Dujaily, K. Y. (2016). Baghdad Sci. J., 13(4): 714-720.

[18] Desmonts, G. Couvreur, J. and Bull, N.Y. (1974). 50:146-159.

[19] Shchuruk, Nv (2018). Peculiarities Of Cytokin Balance In Women With History Of Reproductive Losses In The Dynamics Of Complicated And Uncompressed Pregnancy. Current Issues Of Pediatrics, Obstetrics And Gynecology, (1). Https://Doi.Org/10.11603/24116-4944.2018.1.8803

[20] Bränn, E.; Edvinsson, Å; Punga, A. R.; Sundström-Poromaa, I.; Skalkidou, A. (2019). Scientific reports, 9(1): 1-10.

[21] Dutta, S. ; Sengupta, P. (2017). J Preg. Reprod., 1(4): 1-3.

[22] Paradisi, R.; Porcu, E.; Venturoli, S.; Maldini-Casadei, M. ; Boni, P. (2003). American J. Reprod. Immun., 50(4): 302-308.

[23] Al-Hilli, N. M. (2009). Med. J. Babylon, 6(3-4): 521-526.

[24] Daher, S.; Denardi, K. D. A. G.; Blotta, M. H. S. L.; Mamoni, R. L.; Reck, A. P. M.; Camano, L.; Mattar, R. (2004). J.Reprod. Immun., 62(1-2), 151-157.

[25] Kim, H. R.; Park, A. J.; Lee, M. K. ; Cho, D. H. (2006). Korean J. labo. Med., 26(3): 198-203.

[26] Okpalaji, C.; Okerengwo, A.; Okpani, A.; Chinko, B. ; Bamigbowu, E. (2016). IOSR J. Dent. Med. Sci. 15(09): 77-79. 
[27] Ebadi, P.; Solhjoo, K.; Bagheri, K.; Eftekhar, F. (2011). J Jahrom Univ. Med. Sci., 9(1): 33-37. [28] Al-Masoudi, H. K. (2015). Med. J. Babylon, 12(4) , 934-942.

[29] Mohammed, L. J. and Al-Janabi, M. S. (2019). Med. J. Babylon, 16(3) , 188-191.

[30] Al-Sray, A. H.; Sarhan, S. R. ; Mohammed, H. A. (2019). Adv. Anim. Vet. Sci., 7(8): 657-663.

[31] Ismael, A. K. and Salih, T. A. (2019). Baghdad Sci. J., 16(3): 697-706. 